\title{
Erratum to: Stability of auditory event-related potentials in coma research
}

\author{
Barbara Schorr ${ }^{1,2} \cdot$ Winfried Schlee ${ }^{3}$ Marion Arndt ${ }^{1}$ - Dorothée Lulé ${ }^{4}$. \\ Iris-Tatjana Kolassa ${ }^{2} \cdot$ Alex Lopez-Rolon $^{5} \cdot$ Andreas Bender $^{1,5}$
}

Published online: 17 April 2015

(C) Springer-Verlag Berlin Heidelberg 2015

\section{Erratum to: J Neurol (2015) 262:307-315 DOI 10.1007/s00415-014-7561-y}

In the original article, one of the co-authors' (Alex LopezRolon) given name has been published incorrectly as Alexander Lopez-Rolon. The correct name should be Alex Lopez-Rolon.

The online version of the original article can be found under doi:10.1007/s00415-014-7561-y.

Barbara Schorr

barbara.schorr@uni-ulm.de

1 Therapiezentrum Burgau, Kapuzinerstraße 34, 89331 Burgau, Germany

2 Clinical and Biological Psychology, Institute of Psychology and Education, University of Ulm, Albert-Einstein-Allee 47, 89069 Ulm, Germany

3 Institute for Psychiatry and Psychotherapy, University of Regensburg, Universitätsstraße 84, 93053 Regensburg, Germany

4 Department of Neurology, University of Ulm, Oberer Eselsberg 45, 89081 Ulm, Germany

5 Department of Neurology, Klinikum Grosshadern, University of Munich, Marchioninistraße 15, 81377 Munich, Germany 